OPEN ACCESS

Edited by:

Lei Xi,

Virginia Commonwealth University,

United States

Reviewed by:

Arnab K Chatterjee,

Calibr at Scripps Research,

United States

Kirill Gorshkov,

National Center for Advancing

Translational Sciences (NCATS),

United States

Daniel F Alonso,

National University of Quilmes,

Argentina

*Correspondence:

Felix Hammann

Felix.Hammann@insel.ch

${ }^{\dagger}$ These authors have contributed equally to this work

Specialty section:

This article was submitted to Translational Pharmacology,

a section of the journal

Frontiers in Pharmacology

Received: 03 November 2020 Accepted: 21 January 2021

Published: 10 March 2021

Citation:

Kern C, Schöning V, Chaccour C and Hammann F (2021) Modeling of SARSCoV-2 Treatment Effects for Informed Drug Repurposing.

Front. Pharmacol. 12:625678. doi: $10.3389 /$ fphar.2021.625678

\section{Modeling of SARS-CoV-2 Treatment Effects for Informed Drug Repurposing}

\author{
Charlotte Kern ${ }^{1,2 \dagger}$, Verena Schöning ${ }^{1 \dagger}$, Carlos Chaccour ${ }^{3,4,5}$ and Felix Hammann ${ }^{1 *}$ \\ ${ }^{1}$ Clinical Pharmacology and Toxicology, Department of General Internal Medicine, Inselspital (Bern University Hospital), University \\ of Bern, Bern, Switzerland, ${ }^{2}$ Graduate School for Health Sciences, University of Bern, Bern, Switzerland, ${ }^{3}$ ISGlobal, Hospital \\ Clínic-Universitat de Barcelona, Barcelona, Spain, ${ }^{4}$ Clínica Universidad de Navarra, Pamplona, Spain, ${ }^{5}$ Ifakara Health Institute, \\ Ifakara, Tanzania
}

Several repurposed drugs are currently under investigation in the fight against coronavirus disease 2019 (COVID-19). Candidates are often selected solely by their effective concentrations in vitro, an approach that has largely not lived up to expectations in COVID-19. Cell lines used in in vitro experiments are not necessarily representative of lung tissue. Yet, even if the proposed mode of action is indeed true, viral dynamics in vivo, host response, and concentration-time profiles must also be considered. Here we address the latter issue and describe a model of human SARS-CoV-2 viral kinetics with acquired immune response to investigate the dynamic impact of timing and dosing regimens of hydroxychloroquine, lopinavir/ritonavir, ivermectin, artemisinin, and nitazoxanide. We observed greatest benefits when treatments were given immediately at the time of diagnosis. Even interventions with minor antiviral effect may reduce host exposure if timed correctly. Ivermectin seems to be at least partially effective: given on positivity, peak viral load dropped by $0.3-0.6$ log units and exposure by 8.8-22.3\%. The other drugs had little to no appreciable effect. Given how well previous clinical trial results for hydroxychloroquine and lopinavir/ritonavir are explained by the models presented here, similar strategies should be considered in future drug candidate prioritization efforts.

Keywords: COVID-19, disease modeling, drug repurposing, viral kinetics, pharmacometrics

\section{INTRODUCTION}

Since the beginning of the ongoing global outbreak of severe acute respiratory syndrome coronavirus 2 (SARS-CoV-2), a variety of drug therapies have been proposed. Some are based on expert opinion, some on promising in vitro results, some on findings in case series from compassionate or off-label treatments. Unfortunately, whenever they are put through the rigorous process of randomized clinical trials, little evidence for palpable real-world benefits remains.

Novel coronavirus disease 2019 (COVID-19) spreads rapidly not only from host to host but within each host as well. The infection progresses at a staggering speed in individual patients which may become infectious after $2-3$ days and reach peak viral loads only a few days after the reversetranscriptase polymerase chain reaction (RT-PCR) test becomes positive (To et al., 2020). The need for early initiation of drug therapy has been recognized as key for successful treatment of infectious diseases, and COVID-19 is unlikely to be an exception (Gonçalves et al., 2020).

The repurposing of drugs with established supply chains and low manufacturing costs seems the straightest path towards a timely pharmacological intervention. Because our understanding of the 
pathophysiology of COVID-19 is still evolving, the selection of viable candidates is mostly dictated by extrapolations from in vitro and in silico evidence. Identified drug targets include the viral structural spike (S) protein; the host type 2 transmembrane serine protease (TMPRSS2); 3-chymotrypsinlike (3CL) protease mediating proteolysis; RNA-dependent RNA polymerase; and interleukin-6 receptors (Arshad et al., 2020; Sanders et al., 2020).

A basic tenant of clinical pharmacology states that an unbound drug must reach its target at sufficient concentrations (e.g., halfmaximal effective target concentrations $\left(\mathrm{EC}_{50}\right)$ ) and maintain them to exert effects. This is a common criterion for drug candidate selection and has been applied to COVID-19 early on in well-conducted comprehensive surveys (Arshad et al., 2020). Unfortunately, the candidates with highest probability of success have largely failed in practice, and it appears that the $\mathrm{EC}_{50}$ approach might be too simplistic for this disease, as it is important not only whether $\mathrm{EC}_{50}$ is reached, but also for how long concentrations (above $\mathrm{EC}_{50}$ ) can be maintained, especially at the target site.

One reason may be the failure to account for host factors. For instance, a crucial element of treatment response is host immunity. There are in vivo studies on the temporal dynamics of immune response and seroconversion (Long et al., 2020; To et al., 2020; Young et al., 2020). Early suppression of viral load even for brief periods may be beneficial by providing more time for the host to mount a defense and assist in clearing an otherwise overwhelming infection.

The viral kinetics of several diseases have been successfully described mathematically in the past, e.g., influenza, hepatitis $C$, or Ebola (Beauchemin and Handel, 2011; Canini and Perelson, 2014; Oakes et al., 2018). For COVID-19, Kim et al. used a target cell limited model to show the importance of early initiation of treatment and drug mode of action (Kim et al., 2020b). Other authors arrive at similar results with eclipse models (Czuppon et al., 2020; Gonçalves et al., 2020; Hernandez-Vargas and Velasco-Hernandez, 2020). None of these studies, however, directly used pharmacokinetic profiles in their models.

With this modeling and simulation study, we aimed to understand the influence of different modes of action, concentration profiles, dosing schedules, and timing of interventions on key parameters of viral load (peak load, duration of positivity, and total exposure as measured by area under the curve (AUC)) in acute COVID-19. We developed a model of the within-host viral kinetics of SARSCoV-2 from published patient data and drove antiviral effect with simulated pharmacokinetic $(\mathrm{PK})$ profiles of selected drugs with different dose regimens. These drugs include hydroxychloroquine (HCQ, considered a blocker of viral entry), ritonavir-boosted lopinavir (LPV/r, a 3CL inhibitor), ivermectin (IVM, a broad spectrum anthelminthic with antiviral activity), nitazoxanide (NZT, an antiparasitic agent with antiviral activity), and artemisinin (ART, the primary component of sweet wormwood, believed to inhibit viral entry and intracellular reproduction of SARS-CoV-2) (Caly et al., 2020; Choy et al., 2020; Gordon et al., 2020; Li et al., 2005; Liu et al., 2020; Wang et al., 2020a; Wu et al., 2020). Our selection was influenced by perceived research interest (HCQ, $\mathrm{LPV} / \mathrm{r}, \mathrm{NZT}$ ) and lay use of drugs in the general public as selfmedication (HCQ, IVM, ART) (Martins-Filho et al., 2020; Molento, 2020; Nordling, 2020; Owens, 2020; WHO, 2020). Although remdesivir has so far shown the greatest promise, there is currently not enough published data to allow for pharmacometric simulation in the model proposed here, and hence the drug was not included (Beigel et al., 2020).

\section{METHODS}

\section{Data Sources}

Viral kinetic profiles of COVID-19 patients were taken from Young et al. (2020), a study that followed the first patients $(n=$ 18 ) in four hospitals in Singapore (Chinese nationals: $n=16$, Singapore residents: $n=2$ ). We read out values using a digitizing software. Most $(n=13)$ were not on specific therapy and were included in the analysis. Viral load was measured from nasopharyngeal swabs with RT-PCR and presented in cycle threshold (Ct) values (Young et al., 2020). As the correlation between $\mathrm{Ct}$ values and viral load varies by laboratory and analytical conditions, we chose to relate model output with observed $\mathrm{Ct}$ values with a published regression fit (Chu et al., 2020). Since the time of infection was not recorded, this value had to be estimated. Although the incubation period varies between patients, an average incubation period of 5 days fitted well for all patients (Lauer et al., 2020). We fixed the positivity threshold at 35 cycles, corresponding to $10^{1.58}$ copies $/ \mathrm{ml}$ (Wang et al., 2020b).

\section{Viral Kinetics Models}

In the standard target cell limited model, virus particles $V$ infect a pool of susceptible (target) cells $T$ with the cellular infection rate $\beta$. Infected cells $I$ begin shedding virions at a production rate $p$ (Canini and Perelson, 2014). The parameters $c$ and $\delta$ determine the rate of clearance of virus and cell death of infected cells, respectively. The time-dependent number of susceptible cells (Eq. (1)), infected cells (Eq. (2)), and viral load (Eq. (3)) are described by a system of ordinary differential equations as follows:

$$
\begin{aligned}
& \frac{d T}{d t}=-(1-\eta) \beta T V, \\
& \frac{d I}{d t}=(1-\eta) \beta T V-\delta I, \\
& \frac{d V}{d t}=(1-\varepsilon) p I-c V .
\end{aligned}
$$

The effects of pharmacological treatments by different modes of action are described by the following variables: inhibition of viral entry into susceptible cells, by decreasing the cellular infection rate with effectiveness $\eta$, and/or by blocking viral production rate within infected cells with effectiveness $\varepsilon$. We modeled treatment effect based on the $\mathrm{IC}_{50}$ or $\mathrm{EC}_{50}$ values of the drugs on their respective targets using a sigmoidal $\mathrm{E}_{\max }$ model (Eq. (4)), with $C(t)$ being the concentration of the drug at a given time: 


$$
\varepsilon \text { or } \eta=\frac{E_{\text {max }} \times C(t)}{E C_{50}+C(t)} .
$$

We also considered an eclipse model, an extension in which infected cells enter an eclipse phase $(E)$ for an average duration $k^{-1}$ until they begin shedding virions. Initial conditions were set as

$$
\begin{aligned}
T(0) & =T_{0}, \\
V(0) & =V_{0}, \\
I(0) & =0,
\end{aligned}
$$

and additionally, for the eclipse model,

$$
E(0)=0
$$

where $\mathrm{T}_{0}$ is the number of susceptible cells fixed to $1 \times 10^{5}$ (based on prior modeling efforts and accounting for $\sim 1 \%$ of alveolar cells expressing ACE2, the main point of entry for SARS-CoV-2) (Baccam et al., 2006; $\mathrm{Li}$ et al., 2020b), $\mathrm{V}_{0}$ the initial viral load on inoculation (fixed at $1 \times 10^{0}$ copies $/ \mathrm{ml}$ ), and $\mathrm{E}_{0}$ the number of cells in eclipse state. The within-host reproduction number $\mathrm{R}_{0}$ was set to 3.79 ( $\mathrm{Li}$ et al., 2020a). This value is also approximately in the same range as other within-host virus kinetic models (Kim et al., 2020b; Hernandez-Vargas and Velasco-Hernandez, 2020). Other parameters need to be estimated by numerical optimization, i.e., viral clearance $c$, the production rate $p$, and the death rate of infected cells $\delta$. The cellular infection rate $\beta$ of the virus is dynamically calculated:

$$
\beta=\frac{c \delta R_{0}}{\left(p-\delta R_{0}\right) T_{0}} .
$$

Supplementary Table S2 shows all model parameters and sources.

\section{Immune Response}

Our understanding of SARS-CoV-2 immunity is still evolving. Immunity could involve cells entering into a refractory state or an antibody-mediated increase in viral clearance. Adding an additional state would increase model complexity beyond what seems supported by the source data. We therefore chose to enter acquired immune response as a time-dependent covariate effect on viral clearance $c$. Temporal dynamics are based on Long et al. (2020) who evaluated seroconversion for IgM and IgG in 285 patients from three hospitals in Chongqing (neighboring Hubei Province). Data were extracted with a digitizing software and fitted to a sigmoidal $\mathrm{E}_{\max }$ model. As the effect size of the immune response in SARS-CoV-2 infection ( $\mathrm{E}_{\max }$, immunity) is unknown, we estimated this value together with the models of viral kinetics.

\section{Pharmacokinetic Models}

We simulated pharmacokinetics (PK) of HCQ, IVM, LPV/r, and ART from published population pharmacokinetics models. Profiles for HCQ were simulated from healthy volunteers reported by Lim et al. (2009). The IVM model was taken from Duthaler et al. and simulated using fed state dosing (Duthaler et al., 2019). The LPV/r model by Dickinson et al. (2011) was built from data of healthy volunteers receiving $400 / 100 \mathrm{mg}$, the dose that was under investigation in WHO Solidarity. For ART we directly implemented the model developed by Birgersson et al. in healthy male volunteers with a dosing regimen of $500 \mathrm{mg}$ daily for 5 days (similar to historical dosing recommendations in malaria) (Birgersson et al., 2016). No published pharmacometric model is available for NTZ. The drug is rapidly and completely hydrolysed to an active metabolite, tizoxanide (TZ). We therefore extracted the mean $\mathrm{TZ}$ pharmacokinetic profile from a study in healthy Mexican volunteers with a digitizing software, fitted a onecompartment oral absorption model with lag time, and used this for simulation (Balderas-Acata et al., 2011).

As the protein-bound fraction of a drug is considered not interacting with its target, we only considered the unbound fractions of the drugs to be available (Supplementary Table S2), i.e. 50\% for HCQ (Furst, 1996), 7\% for IVM (Klotz et al., 1990), 1\% for NTZ (FDA, 2005), and 1\% for LPV (Boffito et al., 2004). No human in vivo data exist for lung concentrations in any of the drugs in this study. We used literature-based approximations to adjust for differences between plasma and lung concentration profiles. The issue of lung tissue concentrations is particularly contentious for HCQ, with some reports of lung:plasma ratio ranging from 27 to 177 in macaques (Maisonnasse et al., 2020). Recent evidence suggests that in COVID-19 HCQ plasma concentrations are more representative (Fan et al., 2020). For IVM lung accumulation, we used cattle data published by Lifschitz et al., an approach also used in another publication discussing the potential role of IVM in COVID-19 (Lifschitz et al., 2000; Schmith et al., 2020). LPV concentrations in lung tissue were assumed to be 1.78 times higher than in plasma, and protein binding was set to $99 \%$ (Atzori et al., 2003; FDA, 2013). For NTZ we used estimates from a recently prepublished physiology-based pharmacokinetic (PBPK) model for lung partitioning (Rajoli et al., 2020).

\section{Pharmacodynamic Effects}

The effectiveness of HCQ was shown in vitro in Vero E6 cells by Liu et al. (2020). The $\mathrm{EC}_{50}$ values at $48 \mathrm{~h}$ ranged between 4.06 and $12.96 \mu \mathrm{M}$, depending on the amount inoculated. We entered the mean of these values $(8.51 \mu \mathrm{M})$ as an effect on the reduction of the cellular infection rate $\beta$. We simulated dosages of $200 \mathrm{mg}$ q8h for 10 days as proposed by Gautret et al. and the scheme previously employed in the WHO Solidarity trial, $800 \mathrm{mg}$ q12 h on the first day (loading dose) and $400 \mathrm{mg} \mathrm{q12}$ h on days 2-10 (Gautret et al., 2020; WHO, 2020).

For IVM, we assumed two pharmacodynamic effects: the inhibition of RNA helicase and inhibition of nicotinic acetylcholine receptors (nAChR). The inhibitory effect of IVM on helicase has been previously reported for flaviviridae, i.e., yellow fever virus (YFV, $\mathrm{IC}_{50} 0.12 \mu \mathrm{M}$ ), Dengue virus (DENV, IC $\mathrm{IC}_{50} 0.5 \mu \mathrm{M}$ ), and West Nile Virus (WNV, IC $\mathrm{I}_{50}$ $0.35 \mu \mathrm{M}$ ) (Mastrangelo et al., 2012). There are no in vitro data for SARS-CoV-2 yet, although Caly et al. (2020) have reported a strong maximal inhibition of virus replication in the Vero E6 cell line with an $\mathrm{IC}_{50}$ of about $2 \mu \mathrm{M}$. Higher concentrations $(10-25 \mu \mathrm{M})$ need to be achieved for similar inhibition of DENV replication (Wagstaff et al., 2012). The difficulties in achieving micromolar concentrations have led some authors to 
speculate IVM is not druggable in the context of COVID-19 (Bray et al., 2020). Strikingly, despite the higher $\mathrm{IC}_{50}$ in DENV infected Vero E6 cells, a small trial of IVM $3 \times 400 \mu \mathrm{g} / \mathrm{kg}$ in DENV patients demonstrated antiviral effects in vivo (Yamasmith et al., 2018). Due to the higher susceptibility of SARS-CoV-2 to IVM than DENV in Vero E6 cells, we used a conservatively reduced $\mathrm{IC}_{50}$ of $0.1 \mu \mathrm{M}$ in the simulations as an inhibitory influence on viral production $p$.

In addition, IVM interacts with nAChR ( $\left.\mathrm{IC}_{50} 156 \mathrm{nM}\right)$ (Degani-Katzav et al., 2017). It has been hypothesized that inhibition of $\mathrm{nAChR}$ downregulates angiotensin-converting enzyme 2 (ACE2) expression and thus reduces the points of entry for SARS-CoV-2 (Oakes et al., 2018). We enter this as a net inhibitory effect on the cellular infection rate $\beta$. In contrast to direct inhibition of viral entry, this is an antiviral activity mediated by the host and therefore not easily captured in in vitro assays. For IVM, we evaluated $300 \mu \mathrm{g} / \mathrm{kg}$ and $600 \mu \mathrm{g} / \mathrm{kg}$ q24 h for 3 days. These dosages are not approved, but safety and tolerability of single fixed doses of $120 \mathrm{mg}$ were shown previously in healthy volunteers (Guzzo et al., 2002).

LPV and RTV are both protease inhibitors. Their use in COVID-19 was investigated as a now discontinued arm of the WHO solidarity trial (LPV $400 \mathrm{mg}$ and RTV $100 \mathrm{mg} \mathrm{q} 12 \mathrm{~h}$ for 14 days) (WHO, 2020). LPV reduced the viral RNA copies of SARS-CoV-2 in vitro with an $\mathrm{EC}_{50}$ of $26.1 \mu \mathrm{M}$, whereas RTV has an $\mathrm{EC}_{50}>100 \mu \mathrm{M}$ (Choy et al., 2020). As RTV in this coformulation $(\mathrm{LPV} / \mathrm{r})$ is only intended to boost the bioavailability of LPV, we only consider the antiviral effect of LPV on the viral production rate $p$ (Chandwani and Shuter, 2008).

ART as the main component of $A$. annua (sweet wormwood) extract has not been studied in SARS-CoV-2. Nair et al. reported an antiviral effect in Vero E6 cells of artesiminin on SARS-CoV-2 with an $\mathrm{EC}_{50}$ of $19.8 \mu \mathrm{g} / \mathrm{ml}(=70 \mu \mathrm{M})$ (Nair et al., 2021). Studies suggest that artemisinin interferes with viral entry by interaction with the spike protein (Sehailia and Chemat, 2020), but it also affects postentry steps of infection (Cao et al., 2020b; Nair et al., 2021). We entered this as an effect on viral production rate $p$ and the cellular infection rate $\beta$.

NTZ has shown in vitro activity against SARS-CoV-2 in Vero E6 cells at an $\mathrm{EC}_{50}$ of $2.12 \mu \mathrm{M}$ (Wang et al., 2020a). The mechanism of action is unclear, but it has been hypothesized that NTZ inhibits viral entry as well as replication. We used both effects in the simulations (Arshad et al., 2020).

\section{Software}

We modelled and simulated pharmacokinetic profiles with Pkanalix and mlxR (version 4.1.3), an $\mathrm{R}$ package for interfacing with Monolix (version 2019R2, http://www.lixoft. com, Antony, France). Data for viral loads and NTZ were read out with WebPlotDigitizer (version 4.2, https://automeris.io/ WebPlotDigitizer). Immunity $\mathrm{E}_{\max }$ and $\mathrm{EC}_{50}$ were estimated using the $\mathrm{R}$ package rstanemax (version 0.1.2). Data checkout, analysis, and visualization were performed in GNU R (version 3. 6.3, R Foundation for Statistical Computing, http://www.Rproject.org, Vienna, Austria). Ordinary differential equation (ODE) systems and parameter estimations were implemented with the R packages deSolve (version 1.28) and dfoptim (version 2018.2-1).

\section{RESULTS}

\section{Viral Kinetics Models}

We used the viral load profiles of untreated patients published by Young et al. ( $n=13$, Supplemental Material) (Young et al., 2020). We evaluated target cell limited and eclipse models, both with a time-varying effect on viral clearance $c$ following a sigmoidal $\mathrm{E}_{\max }$ model fitted to reported seroconversion data (Long et al., 2020). The averaged parameters estimates from individual profiles with the Nelder-Mead method were as follows (see also Supplementary Table S1 and Supplementary Figure S1):

- viral clearance $c$ : 5.07,

- production rate $p: 10.2$,

- death rate of infected cells $\delta: 0.54$, and

- maximal immune effect on clearance $\mathrm{E}_{\mathrm{max} \text {,immunity: 57.0. }}$

Nonlinear mixed effects implementations of these models proved less robust to changes in initial estimates and suffered from numerical identifiability problems.

Profiles were best described by a standard target cell limited model. The addition of an eclipse phase did not improve fits and also introduced identifiability issues, as was already noted in another study (Hernandez-Vargas and Velasco-Hernandez, 2020). Left untreated, viral load exceeds the RT-PCR positivity threshold of 35 cycles at $5.4 \mathrm{dpi}$, peaks at $10.2 \mathrm{dpi}$ with a $\mathrm{Ct}$ value of 28.4 cycles, and drops below the positivity limit at $18.9 \mathrm{dpi}$, similar to reports from clinical studies (Kim et al., 2020a; Lauer et al., 2020; To et al., 2020). Total viral exposure (measured as AUC) was 12 '003 days ${ }^{\star} \log ($ copies $/ \mathrm{ml})$.

\section{Dosage and Effectiveness of Treatment}

Temporal impact of treatment is shown as individual curves in Figure 1. Effect on viral exposure as difference in area under the curve (AUC), relative change in duration, and change in peak cycle $(\mathrm{Ct})$ are presented in Figure 2. Full results including changes in peak viral load and duration of disease are available in Supplementary Table S3 and Supplementary Figure S2. The PK curves of the treatments and the corresponding effect on SARS-CoV-2 viral kinetics are shown in Supplementary Figures S2-S5.

HCQ reduced peak viral load by $0.2-0.3 \log$ units and exposure by $4.6-8.2 \%$ when given on positivity. Treatment starting around peak viral load (10.2 dpi) had no appreciable effect on total viral load or duration of disease. Between both dose regimens, the WHO Solidarity trial arm resulted in the more pronounced reduction in total viral load. Effects of IVM were even more pronounced: given on positivity, peak viral load dropped by $0.3-0.6 \log$ units and exposure by $8.8-22.3 \%$. Exposure reductions are associated with slightly prolonged durations of shedding from 13.5 days (untreated) to 14.2-15.6 days for IVM and 14.1-14.5 days for HCQ, and a 


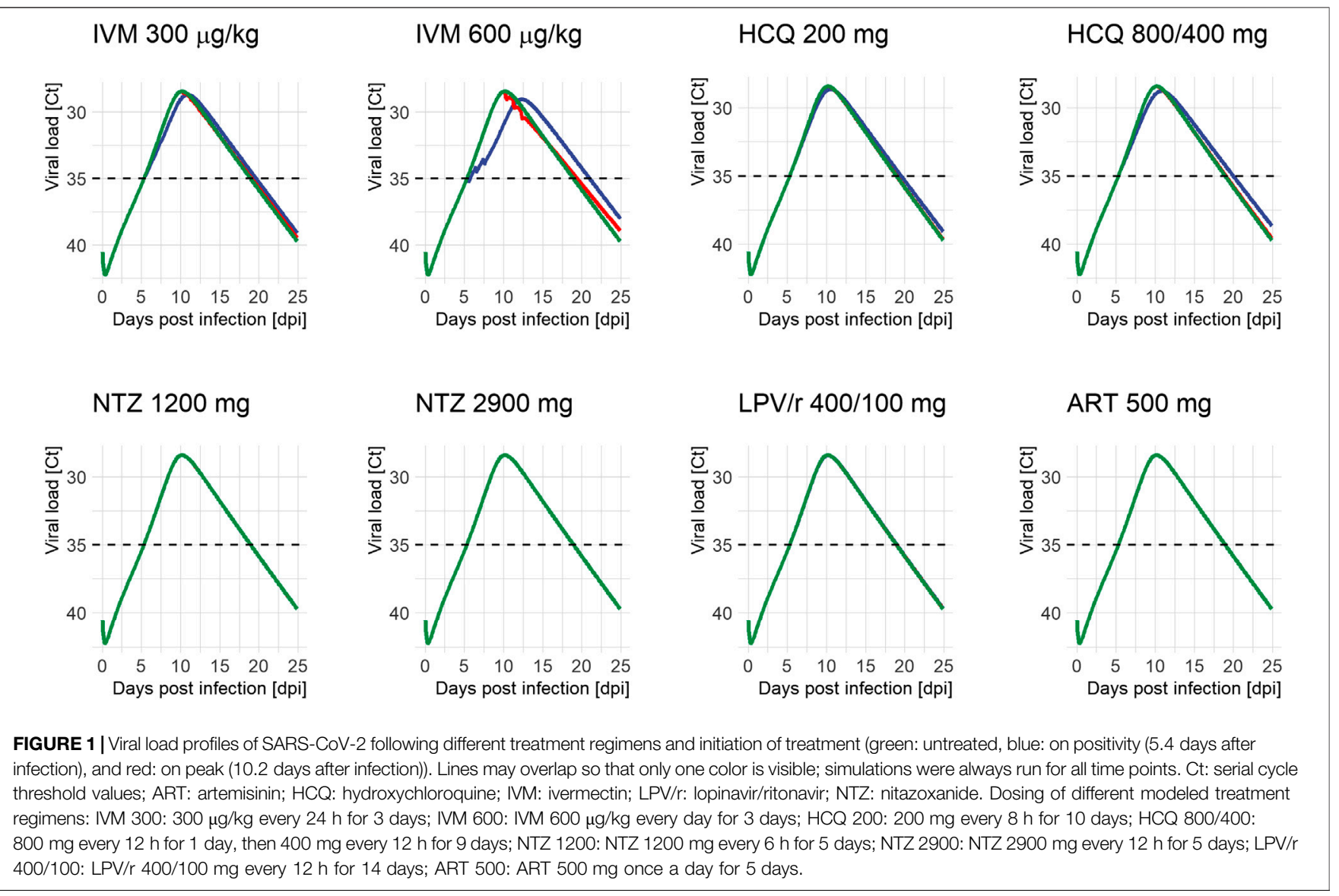

shift of $\mathrm{T}_{\max }$ from day 10.2 (untreated) to day 10.9-12.3 and day 10.5-10.9, respectively. Interestingly-and in contrast to HCQ_-some effects remain when treatment is initiated around peak viral load (3.4-13.2\% difference in exposure). LPV/r, ART, and NTZ had no influence on viral dynamics, independent of time of initiation.

\section{DISCUSSION}

Our modeling and simulation study described patient viral load well and captured the essential milestones of SARS-CoV-2 viral kinetics, e.g., duration of viral shedding and peak viral loads. It also shows that the window of opportunity to treat COVID-19 is narrow. As the infection spreads rapidly throughout the host, the pool of susceptible cells is quickly depleted. Drugs inhibiting viral entry (like HCQ) therefore only appear to have a role, if any, in the first days after inoculation (post-exposure prophylaxis) or as primary prophylactic agents handed out to at-risk individuals.

These findings may help to explain the disappointing results of clinical trials with HCQ: by the time patients are hospitalized or even transferred to critical care, few susceptible cells are left, so little impact can be made at this point (Annie et al., 2020; Cavalcanti et al., 2020; Molina et al., 2020; Tang et al., 2020a). The WHO Solidarity trial's dosing scheme was clearly more effective than the one proposed by Gautret et al. (2020). However, even with the higher dosing scheme used in the WHO Solidarity trial, no appreciable effect of HCQ was observed and the treatment arm was prematurely terminated on June 18, 2020 (Pan et al., 2020). Of note, recent trials have also failed to find benefits for HCQ in pre- and post-exposure prophylactic indications (Boulware et al., 2020; Rajasingham et al., 2020). Since viral load is not the only determinant of disease state, one cannot directly deduce clinical effect of any of the regimens from these simulations. Given the negative results of previous trials with HCQ, we suggest that HCQ results should be used as a lower threshold to rank other drugs against.

We found greatest effects for IVM. Again, the earlier and longer the exposure, the better, but compounds like IVM still convey some benefit if initiated at a later stage. When held to the HCQ benchmark, IVM $600 \mu \mathrm{g} / \mathrm{kg}$ daily for 3 days, particularly when given around time of positivity, may have meaningful impact whereas IVM $300 \mu \mathrm{g} / \mathrm{kg}$ daily for 3 days had efficacy comparable to HCQ regimens. This finding is in contrast to other analyses suggesting IVM is poorly druggable in COVID-19 (Schmith et al., 2020). It is important to stress that these IVM doses, while apparently safe in healthy volunteers, are far higher than any dose approved for other indications $(1 \times 200 \mu \mathrm{g} / \mathrm{kg}$ to $1 \times 400 \mu \mathrm{g} / \mathrm{kg})$. At $3 \times 600 \mu \mathrm{g} / \mathrm{kg}$ in a $70 \mathrm{~kg}$ patient, doses are similar to the maximum doses (120 $\mathrm{mg}$ single administration) described by Guzzo et al. (2002). Boosting exposure to IVM by 


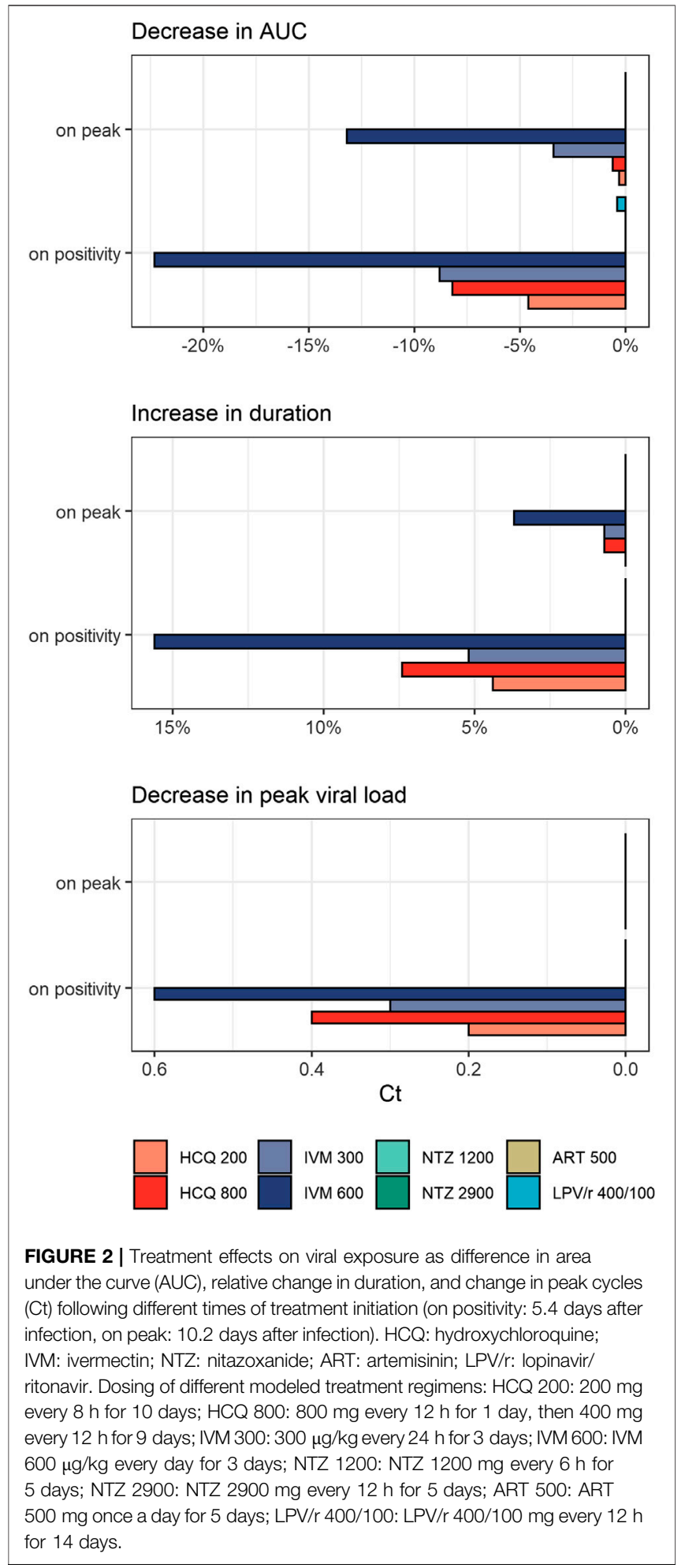

co-administering inhibitors of its metabolism or elimination (such as the CYP3A4 and P-glycoprotein (P-gp) inhibitor ritonavir) is a theoretical option (Chaccour et al., 2017). However, there are concerns that inhibition of P-gp as an integral part of the functional blood brain barrier could lead to more central nervous adverse events (Chandler, 2018). Until this interaction has been studied systematically, it seems unwise to explore this strategy. For IVM, no results of clinical trials regarding its effectiveness in COVID-19 have been published yet.

ART, NTZ, and LPV/r had no noteworthy effect and do not appear suitable candidates for follow-up at this point. We attribute this in part to their strong protein binding (88-99\%), leaving little free drug to engage with targets. Additionally, the $\mathrm{EC}_{50}$ for ART is rather high at $70 \mu \mathrm{M}$ and not likely to be even partially achieved. For LPV/r our findings are confirmed by clinical trial results (Cao et al., 2020a, 24), notably the RECOVERY trial (University of Oxford, 2020) and the WHO Solidarity trial, which discontinued the LPV/r treatment arm on July 4, 2020 (Pan et al., 2020). As of now, no trials on NTZ and ART have reported results.

Our study has several limitations. Our model parameter estimates are based on assumptions of incubation time and number of target cells in the lungs, both of which introduce bias. COVID-19 was initially described from a cluster of pneumonia cases, and while symptoms of the upper and lower airways are most recognizable, vascular, thromboembolic, gastrointestinal, and neurological symptoms have been widely described (Klok et al., 2020; Mao et al., 2020; Struyf et al., 2020; Zhang et al., 2020). Expression levels of ACE2 are also much higher in other tissues, e.g., the small intestine, the kidneys, and the heart (Li et al., 2020b). Hence it seems unlikely that systemic viral loads are solely a product of alveolar epithelial cells. Extent of viral burden is dependent on disease severity and also site of sampling (e.g., oropharyngeal, nasopharyngeal, and plasma (Fajnzylber et al., 2020)). Ethnicity is thought to affect clinical outcomes (Sze et al., 2020), yet there is inconclusive evidence as to the impact of ethnicity on viral load (Magleby et al., 2020). In conclusion, we suggest that the size of the pool of target cells be reestimated in different populations.

Point estimates of viral kinetics parameters yielded realistic estimates of viral load profiles with reasonable uncertainty around point estimates (\%CV: $30-43$ ). We did not normalize the asynchronous dynamics of the source data (e.g., viral peak at different dpi), which might have improved fits. However, currently no accepted procedure exists (Hernandez-Vargas, 2019). Other authors have used more sophisticated methods such as nonlinear mixed effects (nlme) modeling on the same source data, implementing other structural models such as eclipse models (Czuppon et al., 2020; Gonçalves et al., 2020). Our nlme implementations of the models suffered from the same numerical identifiability issues seen by other authors (Hernandez-Vargas and Velasco-Hernandez, 2020). Given that the model presented here is structurally different from other target cell limited or eclipse models, some point estimates can differ from other implementations (such as the reproduction number $R_{0}$, or number of susceptible cells $\mathrm{T}_{0}$ (Gonçalves et al., 2020)).

Virus extinction is not captured by any models like the one proposed here. We therefore decided not to model prophylactic dosing (prior to or on exposure) and resorted to return to negativity on RT-PCR as a surrogate measure for disease duration. This is supported by data suggesting that late stage shedding is of noninfectious virus particles only (Walsh et al., 2020). 
We made several assumptions on modes of drug action and their efficacy. We used the published mode of action of HCQ on SARS-CoV-2, which were performed in the African green monkey kidney-derived cell line Vero (Wang et al., 2020a), even though there is evidence that this cell line might not be suitable to represent lung tissue (Hoffmann et al., 2020). The model places HCQ effects only on viral entry, although it might also have other modes of actions which might affect the production of virions within infected cells (Quiros Roldan et al., 2020; Tripathy et al., 2020). Additionally, HCQ has immunomodulatory effects and might hinder the activation of $\mathrm{B}$ and $\mathrm{T}$ cells and thus inhibit the host-innate immune response (Goldman et al., 2000; Quiros Roldan et al., 2020). No data for SARS-CoV-2 were available for modeling. If relevant at all, our model would be overestimating the effectiveness of HCQ.

The in vitro evidence of efficacy of IVM against SARS-CoV-2 is not detailed enough to model effects with greater precision. Based on data from other flaviviridae, particularly Dengue virus, the proposed inhibition of replication seems reasonable (Mastrangelo et al., 2012). Inclusion of effects on viral entry follows pathophysiological reasoning and has yet to be confirmed in studies. IVM engages with $\mathrm{nAChR}$, which leads to a reduction of ACE2 and in turn decreases the points of entry for SARS-CoV-2, influencing the cellular infection rate. Even though the $\mathrm{IC}_{50}$ for IVM on $\mathrm{nAChR}$ has been experimentally determined, we do not know how exactly this relates to the reduction of ACE2 expression. Therefore, we decided to model it solely based on plasma levels and the available $\mathrm{IC}_{50}$.

In HCQ and IVM, even though total viral load is reduced, the duration of virus shedding might be increased, a consequence of a 'flattening of the curve' similar to what is observed on a population scale. However, this gives the immune response more time to develop an immune response. For this reason, overall total viral load decreases in the simulated models. Changes in peak viral load were moderate at best ( $<1$ log unit). While being convenient endpoints to measure in a clinical setting, AUCs of viral load appear more appropriate for drug discovery.

ART and NZT have only recently received attention in COVID-19 treatment. Despite having little effect in our study, they would make excellent candidates from economic and logistic points of view. We selected ART as it is the primary active ingredient in sweet wormwood. Herbal concoctions of wormwood are being promoted as a cheap, easily accessible form of self-medication in COVID-19 (Welle, 2020). A. annua and derivatives (artesunate, dihydroartesunate) are widely used as antimalarials. Effective concentrations have yet to be determined for ART and its derivatives, although the large degrees of protein binding imply that effective target concentrations need to be in the low micromolar range. Studies suggest that artemisinin has also anti-inflammatory and immunomodulatory effects, which

\section{REFERENCES}

Annie, F. H., Sirbu, C., Frazier, K. R., Broce, M., and Lucas, B. D. (2020). Hydroxychloroquine in hospitalized COVID-19 patients: real world experience assessing mortality. Pharmacotherapy 40, 1072-1081. doi:10. 1002/phar.2467 might be beneficial when treating COVID-19 (Tang et al., 2020b). However, as these effects are not related to viral kinetics, we were not able to include these in our simulations. Even then its use would have one crucial limitation: the WHO is discouraging use of oral artemisinin monotherapy (AMT) in malaria as it is considered to be a major factor for the development of parasite resistance (WHO, 2014). A renaissance of oral AMT in malaria endemic regions during the ongoing COVID-19 pandemic could cause more harm than good.

For NTZ, pharmacokinetic simulations were based on a mean curve of a single dose of NTZ $500 \mathrm{mg}$. The $\mathrm{EC}_{50}$ value was determined for NTZ, not the immediately formed active metabolite tiaxozanide, which would be the active compound expected to reach tissue (Wang et al., 2020a). When more detailed results for tiaxozanide are available, simulated efficacy could change.

In conclusion, while in vitro studies are very well suited to identify possible modes of actions of potential treatments for COVID-19, they are unable to predict the clinical efficacy of a drug. Our simulation of treatments fitted well with available results from clinical trials, even though several estimations had to be made and limitations accepted. Although early initiation was a strong determinant for treatment effect, none of the interventions studied showed major impact on viral dynamics. Efforts should focus on identification of more efficacious drug candidates and vaccine development. Until then, general social and hygiene measures remain the best interventions to combat COVID-19.

\section{DATA AVAILABILITY STATEMENT}

The original contributions presented in the study are included in the article/Supplementary Material, further inquiries can be directed to the corresponding author. The source code is available on GitHub: https://github.com/cptbern/sars2-viral-kinetics.

\section{AUTHOR CONTRIBUTIONS}

FH conceived the project; CK, VS, and FH performed the analyses; and $\mathrm{FH}, \mathrm{CK}$, and VS wrote the first draft of the manuscript. All authors revised and approved the final manuscript.

\section{SUPPLEMENTARY MATERIAL}

The Supplementary Material for this article can be found online at: https://www.frontiersin.org/articles/10.3389/fphar.2021.625678/ full\#supplementary-material.

Arshad, U., Pertinez, H., Box, H., Tatham, L., Rajoli, R. K. R., Curley, P., et al. (2020). Prioritization of anti-SARS-cov-2 drug repurposing opportunities based on plasma and target site concentrations derived from their established human pharmacokinetics. Clin. Pharmacol. Ther. 108, 775-790. doi:10.1002/cpt.1909 Atzori, C., Villani, P., Regazzi, M., Maruzzi, M., and Cargnel, A. (2003). Detection of intrapulmonary concentration of lopinavir in an HIV-infected patient. AIDS 17, 1710-1711. doi:10.1097/01.aids.0000076289.54156.32 
Baccam, P., Beauchemin, C., Macken, C. A., Hayden, F. G., and Perelson, A. S. (2006). Kinetics of influenza A virus infection in humans. J Virol 80, 7590-7599. doi:10.1128/JVI.01623-05

Balderas-Acata, J. I., Ríos-Rogríguezbueno, E. P., Pérez-Becerril, F., EspinosaMartínez, C., Burke-Fraga, V., and Parra, M. G.-D. L. (2011). Bioavailability of two oral-suspension formulations of a single dose of nitazoxanide $500 \mathrm{mg}$ : an open-label, randomized-sequence, two-period crossover, comparison in healthy fasted Mexican adult volunteers. J Bioequiv Availab 3, 43-47. doi:10. 1016/j.clinthera.2009.08.004

Beauchemin, C. A., and Handel, A. (2011). A review of mathematical models of influenza A infections within a host or cell culture: lessons learned and challenges ahead. BMC Public Health 11 (Suppl. 1), S7. doi:10.1186/14712458-11-S1-S7

Beigel, J. H., Tomashek, K. M., Dodd, L. E., Mehta, A. K., Zingman, B. S., Kalil, A. C., et al. (2020). Remdesivir for the treatment of covid-19 - preliminary report. N Engl J Med. 383, 1813-1826. doi:10.1056/NEJMoa2007764

Birgersson, S., Van Toi, P., Truong, N. T., Dung, N. T., Ashton, M., Hien, T. T., et al. (2016). Population pharmacokinetic properties of artemisinin in healthy male Vietnamese volunteers. Malar J. 15, 90. doi:10.1186/s12936016-1134-8

Boffito, M., Hoggard, P. G., Lindup, W. E., Bonora, S., Sinicco, A., Khoo, S. H., et al. (2004). Lopinavir protein binding in vivo through the 12-hour dosing interval. Ther. Drug Monit. 26, 35-39. doi:10.1097/00007691-200402000-00008

Boulware, D. R., Pullen, M. F., Bangdiwala, A. S., Pastick, K. A., Lofgren, S. M., Okafor, E. C., et al. (2020). A randomized trial of hydroxychloroquine as postexposure prophylaxis for covid-19. New England Journal of Medicine 383, 517-525. doi:10.1056/NEJMoa2016638

Bray, M., Rayner, C., Noël, F., Jans, D., and Wagstaff, K. (2020). Ivermectin and COVID-19: a report in Antiviral Research, widespread interest, an FDA warning, two letters to the editor and the authors' responses. Antiviral Res. 178, 104805. doi:10.1016/j.antiviral.2020.104805

Caly, L., Druce, J. D., Catton, M. G., Jans, D. A., and Wagstaff, K. M. (2020). The FDA-approved drug ivermectin inhibits the replication of SARS-CoV2 in vitro. Antiviral Res. 178, 104787. doi:10.1016/j.antiviral.2020.104787

Canini, L., and Perelson, A. S. (2014). Viral kinetic modeling: state of the art. J Pharmacokinet Pharmacodyn 41, 431-443. doi:10.1007/s10928-014-9363-3

Cao, B., Wang, Y., Wen, D., Liu, W., Wang, J., Fan, G., et al. (2020a). A trial of lopinavir-ritonavir in adults hospitalized with severe covid-19. New England J. Medicine 382, 1787-1799. doi:10.1056/NEJMoa2001282

Cao, R., Hu, H., Li, Y., Wang, X., Xu, M., Liu, J., et al. (2020b). Anti-SARS-CoV-2 potential of artemisinins in vitro. ACS Infect Dis. 6, 2524-2531. doi:10.1021/ acsinfecdis.0c00522

Cavalcanti, A. B., Zampieri, F. G., Rosa, R. G., Azevedo, L. C. P., Veiga, V. C., Avezum, A., et al. (2020). hydroxychloroquine with or without azithromycin in mild-to-moderate covid-19. N Engl J Med. 383, 2041-2052. doi:10.1056/ NEJMoa2019014.E

Chaccour, C., Hammann, F., and Rabinovich, N. R. (2017). Ivermectin to reduce malaria transmission I. Pharmacokinetic and pharmacodynamic considerations regarding efficacy and safety. Malar J 16, 161. doi:10.1186/ s12936-017-1801-4

Chandler, R. E. (2018). Serious neurological adverse events after ivermectin-do they occur beyond the indication of onchocerciasis? Am J Trop Med Hyg 98, 382-388. doi:10.4269/ajtmh.17-0042

Chandwani, A., and Shuter, J. (2008). Lopinavir/ritonavir in the treatment of HIV1 infection: a review. Ther Clin Risk Manag. 4, 1023-1033. doi:10.2147/tcrm. s3285

Choy, K. T., Wong, A. Y., Kaewpreedee, P., Sia, S. F., Chen, D., Hui, K. P. Y., et al. (2020). Remdesivir, lopinavir, emetine, and homoharringtonine inhibit SARSCoV-2 replication in vitro. Antiviral Res. 178, 104786. doi:10.1016/j.antiviral. 2020.104786

Chu, D. K. W., Pan, Y., Cheng, S. M. S., Hui, K. P. Y., Krishnan, P., Liu, Y., et al. (2020). Molecular diagnosis of a novel coronavirus (2019-nCoV) causing an outbreak of pneumonia. Clin Chem. 66, 549-555. doi:10.1093/clinchem/ hvaa029

Czuppon, P., Débarre, F., Gonçalves, A., Tenaillon, O., Perelson, A. S., Guedj, J., et al. (2020). Predicted success of prophylactic antiviral therapy to block or delay SARS-CoV-2 infection depends on the targeted mechanism. medRxiv. doi:10.1101/2020.05.07.20092965
Degani-Katzav, N., Klein, M., Har-Even, M., Gortler, R., Tobi, R., and Paas, Y. (2017). Trapping of ivermectin by a pentameric ligand-gated ion channel upon open-to-closed isomerization. Sci Rep. 7, 42481. doi:10.1038/srep42481

Dickinson, L., Boffito, M., Back, D., Else, L., Von Hentig, N., Davies, G., et al. (2011). Sequential population pharmacokinetic modeling of lopinavir and ritonavir in healthy volunteers and assessment of different dosing strategies. Antimicrob Agents Chemother. 55, 2775-2782. doi:10.1128/AAC.00887-10

Duthaler, U., Leisegang, R., Karlsson, M. O., Krähenbühl, S., and Hammann, F. (2019). The effect of food on the pharmacokinetics of oral ivermectin. J. Antimicrobial Chemotherapy 75, 438-440. doi:10.1093/jac/dkz466

Fajnzylber, J., Regan, J., Coxen, K., Corry, H., Wong, C., Rosenthal, A., et al. (2020). SARS-CoV-2 viral load is associated with increased disease severity and mortality. Nat Commun. 11, 5493. doi:10.1038/s41467-020-19057-5

Fan, E., Beitler, J. R., Brochard, L., Calfee, C. S., Ferguson, N. D., Slutsky, A. S., et al. (2020). COVID-19-associated acute respiratory distress syndrome: is a different approach to management warranted? Lancet Respir Med 8, 816-821. doi:10. 1016/S2213-2600(20)30304-0

FDA (2005). Prescribing INFORMATION: Alinia ${ }^{\circledR}$ (nitazoxanide) Tablets (nitazoxanide) for oral suspension. Available at: https:// www.accessdata.fda.gov/drugsatfda_docs/label/2005/021818lbl.pdf (Accessed November, 1 2020).

FDA (2013). Prescribing INFORMATION: KALETRA (lopinavir/ritonavir) tablet, film coated for oral use, KALETRA (lopinavir/ritonavir) solution for oral use. Available at: https://www.accessdata.fda.gov/drugsatfda_docs/label/2013/ 021251s046_021906s039lbl.pdf (Accessed November, 1 2020).

Furst, D. E. (1996). Pharmacokinetics of hydroxychloroquine and chloroquine during treatment of rheumatic diseases. Lupus 5 (Suppl 1), S11-S15.

Gautret, P., Lagier, J.-C., Parola, P., Hoang, V. T., Meddeb, L., Mailhe, M., et al. (2020). Hydroxychloroquine and azithromycin as a treatment of COVID-19: results of an open-label non-randomized clinical trial. Inter. J. Antimicrobial Agents 56, 105949. doi:10.1016/j.ijantimicag.2020.105949

Goldman, F. D., Gilman, A. L., Hollenback, C., Kato, R. M., Premack, B. A., and Rawlings, D. J. (2000). Hydroxychloroquine inhibits calcium signals in T cells: a new mechanism to explain its immunomodulatory properties. Blood 95, 3460-3466. doi:10.1182/blood.v95.11.3460

Gonçalves, A., Bertrand, J., Ke, R., Comets, E., De Lamballerie, X., Malvy, D., et al. (2020). Timing of antiviral treatment initiation is critical to reduce SARS-CoV2 viral load. CPT: Pharm. Syst. Pharm. 9, 509-514. doi:10.1002/psp4.12543

Gordon, D. E., Jang, G. M., Bouhaddou, M., Xu, J., Obernier, K., White, K. M., et al. (2020). A SARS-CoV-2 protein interaction map reveals targets for drug repurposing. Nature 583, 459-468. doi:10.1038/s41586-020-2286-9

Guzzo, C. A., Furtek, C. I., Porras, A. G., Chen, C., Tipping, R., Clineschmidt, C. M., et al. (2002). Safety, tolerability, and pharmacokinetics of escalating high doses of ivermectin in healthy adult subjects. J Clin Pharmacol. 42, 1122-1133. doi:10. $1177 / 009127002401382731$

Hernandez-Vargas, E. A., and Velasco-Hernandez, J. X. (2020). In-host mathematical modelling of COVID-19 in humans. Annu Rev Control 50, 448-456. doi:10.1016/j.arcontrol.2020.09.006

Hernandez-Vargas, E. A. (2019). "Chapter 3 - model parameter estimation," in Modeling and control of infectious diseases in the host, Editors. E. Sánchez and E.A. Hernandez-Vargas (Cambridge, MA: Academic Press), 35-61.

Hoffmann, M., Mösbauer, K., Hofmann-Winkler, H., Kaul, A., Kleine-Weber, H., Krüger, N., et al. (2020). Chloroquine does not inhibit infection of human lung cells with SARS-CoV-2. Nature 585, 588-590. doi:10.1038/s41586-020-2575-3

Jagdev, S., and Sidhu, M. A. (1997). Single-dose, comparative study of venous, capillary and salivary artemisinin concentrations in healthy, male adults. The American Journal of Tropical Medicine and Hygiene 56, 13-16. doi:10.4269/ ajtmh.1997.56.13

Kim, J. Y., Ko, J. H., Kim, Y., Kim, Y. J., Kim, J. M., Chung, Y. S., et al. (2020a). Viral load kinetics of SARS-CoV-2 infection in first two patients in korea. J Korean Med Sci. 35, e86. doi:10.3346/jkms.2020.35.e86

Kim, K. S., Ejima, K., Ito, Y., Iwanami, S., Ohashi, H., Koizumi, Y., et al. (2020b). Modelling SARS-CoV-2 dynamics: implications for therapy. MedRxiv. doi:10. $1101 / 2020.03 .23 .20040493$

Klok, F. A., Kruip, M. J. H. A., Van Der Meer, N. J. M., Arbous, M. S., Gommers, D. A. M. P. J., Kant, K. M., et al. (2020). Incidence of thrombotic complications in critically ill ICU patients with COVID-19. Thromb Res. 191, 145-147. doi:10. 1016/j.thromres.2020.04.013 
Klotz, U., Ogbuokiri, J. E., and Okonkwo, P. O.(1990). Ivermectin binds avidly to plasma proteins. Eur J Clin Pharmacol. 39, 607-608. doi:10.1007/BF00316107

Lauer, S. A., Grantz, K. H., Bi, Q., Jones, F. K., Zheng, Q., Meredith, H. R., et al. (2020). The incubation period of coronavirus disease 2019 (COVID-19) from publicly reported confirmed cases: estimation and application. Ann Intern Med. 172, 577-582. doi:10.7326/M20-0504

Li, C., Xu, J., Liu, J., and Zhou, Y. (2020a). The within-host viral kinetics of SARSCoV-2. Math Biosci Eng. 17, 2853-2861. doi:10.3934/mbe.2020159

Li, M. Y., Li, L., Zhang, Y., and Wang, X. S. (2020b). Expression of the SARS-CoV-2 cell receptor gene ACE2 in a wide variety of human tissues. Infect Dis Poverty 9 , 45. doi:10.1186/s40249-020-00662-x

Li, S. Y., Chen, C., Zhang, H. Q., Guo, H. Y., Wang, H., Wang, L., et al. (2005). Identification of natural compounds with antiviral activities against SARSassociated coronavirus. Antiviral Res. 67, 18-23. doi:10.1016/j.antiviral.2005. 02.007

Lifschitz, A., Virkel, G., Sallovitz, J., Sutra, J. F., Galtier, P., Alvinerie, M., et al. (2000). Comparative distribution of ivermectin and doramectin to parasite location tissues in cattle. Vet Parasitol. 87, 327-338. doi:10.1016/s03044017(99)00175-2

Lim, H. S., Im, J. S., Cho, J. Y., Bae, K. S., Klein, T. A., Yeom, J. S., et al. (2009). Pharmacokinetics of hydroxychloroquine and its clinical implications in chemoprophylaxis against malaria caused by Plasmodium vivax. Antimicrob Agents Chemother. 53, 1468-1475. doi:10.1128/AAC.00339-08

Liu, J., Cao, R., Xu, M., Wang, X., Zhang, H., Hu, H., et al. (2020). Hydroxychloroquine, a less toxic derivative of chloroquine, is effective in inhibiting SARS-CoV-2 infection in vitro. Cell Discov. 6, 16. doi:10.1038/ s41421-020-0156-0

Long, Q. X., Liu, B. Z., Deng, H. J., Wu, G. C., Deng, K., Chen, Y. K., et al. (2020). Antibody responses to SARS-CoV-2 in patients with COVID-19. Nat Med. 26, 845-848. doi:10.1038/s41591-020-0897-1

Magleby, R., Westblade, L. F., Trzebucki, A., Simon, M. S., Rajan, M., Park, J., et al. (2020). Impact of SARS-CoV-2 viral load on risk of intubation and mortality among hospitalized patients with coronavirus disease 2019. Clin Infect Dis. doi:10.1093/cid/ciaa851

Maisonnasse, P., Guedj, J., Contreras, V., Behillil, S., Solas, C., Marlin, R., et al. (2020). Hydroxychloroquine in the treatment and prophylaxis of SARS-CoV-2 infection in non-human primates. Virology. doi:10.21203/rs.3.rs-27223/v1

Mao, L., Jin, H., Wang, M., Hu, Y., Chen, S., He, Q., et al. (2020). Neurologic manifestations of hospitalized patients with coronavirus disease 2019 in Wuhan, China. JAMA Neurol. 77, 683-690. doi:10.1001/jamaneurol.2020. 1127

Martins-Filho, P., Barreto-Alves, J., and Fakhouri, R. (2020). Potential role for nitazoxanide in treating SARS-CoV-2 infection. American Journal of Physiology-Lung Cellular and Molecular Physiology 319, L35-L36. doi:10. 1152/ajplung.00170.2020

Mastrangelo, E., Pezzullo, M., De Burghgraeve, T., Kaptein, S., Pastorino, B., Dallmeier, K., et al. (2012). Ivermectin is a potent inhibitor of flavivirus replication specifically targeting NS3 helicase activity: new prospects for an old drug. J Antimicrob Chemother. 67, 1884-1894. doi:10.1093/jac/ dks147

Molento, M. B. (2020). COVID-19 and the rush for self-medication and self-dosing with ivermectin: a word of caution. One Health 10, 100148. doi:10.1016/j. onehlt.2020.100148

Molina, J. M., Delaugerre, C., Le Goff, J., Mela-Lima, B., Ponscarme, D., Goldwirt, L., et al. (2020). No evidence of rapid antiviral clearance or clinical benefit with the combination of hydroxychloroquine and azithromycin in patients with severe COVID-19 infection. Med Mal Infect. 50, 384. doi:10.1016/j.medmal. 2020.03 .006

Nair, M. S., Huang, Y., Fidock, D. A., Polyak, S. J., Wagoner, J., Towler, M. J., et al. (2021). Artemisia annua L. extracts prevent in vitro replication of SARS-CoV-2. bioRxiv. doi:10.1101/2021.01.08.425825

Nordling, L. (2020). Unproven herbal remedy against COVID-19 could fuel drugresistant malaria, scientists warn. Available at: https://www.sciencemag.org/ news/2020/05/unproven-herbal-remedy-against-covid-19-could-fuel-drugresistant-malaria-scientists.

Oakes, J. M., Fuchs, R. M., Gardner, J. D., Lazartigues, E., and Yue, X. (2018). Nicotine and the renin-angiotensin system. Am. J. physiol. Regul. Integr. Comp. Physiol. 315, R895-R906. doi:10.1152/ajpregu.00099.2018
Owens, B. (2020). Excitement around hydroxychloroquine for treating COVID-19 causes challenges for rheumatology. Lancet Rheumatol. 2, e257. doi:10.1016/ S2665-9913(20)30089-8

Pan, H., Peto, R., Karim, Q. A., Alejandria, M., Henao-Restrepo, A. M., García, C. H., et al. (2020). Repurposed antiviral drugs for COVID-19 -interim WHO SOLIDARITY trial results. medRxiv. doi:10.1101/2020.10.15.20209817

Quiros Roldan, E., Biasiotto, G., Magro, P., and Zanella, I. (2020). The possible mechanisms of action of 4-aminoquinolines (chloroquine/ hydroxychloroquine) against Sars-Cov-2 infection (COVID-19): a role for iron homeostasis? Pharmacol Res. 158, 104904. doi:10.1016/j.phrs.2020.104904

Rajasingham, R., Bangdiwala, A. S., Nicol, M. R., Skipper, C. P., Pastick, K. A., Axelrod, M. L., et al. (2020). Hydroxychloroquine as pre-exposure prophylaxis for COVID-19 in healthcare workers: a randomized trial. Clin. Infect. Dis. doi:10.1093/cid/ciaa1571

Rajoli, R. K., Pertinez, H., Arshad, U., Box, H., Tatham, L., Curley, P., et al. (2020). Dose prediction for repurposing nitazoxanide in SARS-CoV-2 treatment or chemoprophylaxis. medRxiv. doi:10.1101/2020.05.01.20087130

Sanders, J. M., Monogue, M. L., Jodlowski, T. Z., and Cutrell, J. B. (2020). Pharmacologic treatments for coronavirus disease 2019 (COVID-19): a review. JAMA 323, 1824-1836. doi:10.1001/jama.2020.6019

Schmith, V. D., Zhou, J., and Lohmer, L. R. L. (2020). The approved dose of ivermectin alone is not the ideal dose for the treatment of COVID-19. Cli. Pharmacol. Ther. 108, 762-765. doi:10.1002/cpt.1889

Sehailia, M., and Chemat, S. (2020). Antimalarial-agent artemisinin and derivatives portray more potent binding to Lys353 and Lys31-binding hotspots of SARS-CoV2 spike protein than hydroxychloroquine: potential repurposing of artenimol for COVID-19. J Biomol Struct Dyn. doi:10.1080/07391102.2020.1796809

Struyf, T., Deeks, J. J., Dinnes, J., Takwoingi, Y., Davenport, C., Leeflang, M. M., et al. (2020). Signs and symptoms to determine if a patient presenting in primary care or hospital outpatient settings has COVID-19 disease. Cochrane Database Syst Rev. 7, CD013665. doi:10.1002/14651858.CD013665

Sze, S., Pan, D., Nevill, C. R., Gray, L. J., Martin, C. A., Nazareth, J., et al. (2020). Ethnicity and clinical outcomes in COVID-19: a systematic review and metaanalysis. EClinicalMedicine 29, 100630. doi:10.1016/j.eclinm.2020.100630

Tang, W., Cao, Z., Han, M., Wang, Z., Chen, J., Sun, W., et al. (2020a). Hydroxychloroquine in patients with mainly mild to moderate coronavirus disease 2019: open label, randomised controlled trial. BMJ 369, m1849. doi:10. 1136/bmj.m1849

Tang, Y., Liu, J., Zhang, D., Xu, Z., Ji, J., and Wen, C. (2020b). Cytokine storm in COVID-19: the current evidence and treatment strategies. Frontiers in Immunology 11, 1708. doi:10.3389/fimmu.2020.01708

To, K. K., Tsang, O. T., Leung, W. S., Tam, A. R., Wu, T. C., Lung, D. C., et al. (2020). Temporal profiles of viral load in posterior oropharyngeal saliva samples and serum antibody responses during infection by SARS-CoV-2: an observational cohort study. Lancet Infect Dis. 20, 565-574. doi:10.1016/S14733099(20)30196-1

Tripathy, S., Dassarma, B., Roy, S., Chabalala, H., and Matsabisa, M. G. (2020). A review on possible modes of action of chloroquine/hydroxychloroquine: repurposing against SAR-CoV-2 (COVID-19) pandemic. Int J Antimicrob Agents 56, 106028. doi:10.1016/j.ijantimicag.2020.106028

University of oxford (2020). Statement from the chief investigators of the randomised evaluation of COVid-19 thERAPY (RECOVERY) trial on lopinavir-ritonavir. Available at: https://www.recoverytrial.net/files/lopinavirritonavir-recovery-statement-29062020_final.pdf (Accessed November, 1 2020).

Wagstaff, K. M., Sivakumaran, H., Heaton, S. M., Harrich, D., and Jans, D. A. (2012). Ivermectin is a specific inhibitor of importin $\alpha / \beta$-mediated nuclear import able to inhibit replication of HIV-1 and dengue virus. Biochem J. 443, 851-856. doi:10.1042/BJ20120150

Walsh, K. A., Jordan, K., Clyne, B., Rohde, D., Drummond, L., Byrne, P., et al. (2020). SARS-CoV-2 detection, viral load and infectivity over the course of an infection. J. Infect. 81, 357-371. doi:10.1016/j.jinf.2020.06.067

Wang, M., Cao, R., Zhang, L., Yang, X., Liu, J., Xu, M., et al. (2020a). Remdesivir and chloroquine effectively inhibit the recently emerged novel coronavirus (2019-nCoV) in vitro. Cell Res. 30, 269-271. doi:10.1038/s41422-020-0282-0

Wang, W., Xu, Y., Gao, R., Lu, R., Han, K., Wu, G., et al. (2020b). Detection of SARS-CoV-2 in different types of clinical specimens. JAMA 323, 1843-1844. doi:10.1001/jama.2020.3786 
Welle, D. (2020). COVID-19: Tests for 'miracle cure' herb Artemisia begin. Available at: https://www.dw.com/en/covid-19-tests-for-miracle-cure-herbartemisia-begin/a-53442366.

WHO (2014). Emergence and spread of artemisinin resistance calls for intensified efforts to withdraw oral artemisinin monotherapy from the market. Available at: http://www. who.int/malaria/publications/atoz/oral-artemisinin-based-monotherapies1 may2014.pdf.

WHO (2020). "Solidarity" clinical trial for COVID-19 treatments. Available at: https://www.who.int/emergencies/diseases/novel-coronavirus-2019/global-researchon-novel-coronavirus-2019-ncov/solidarity-clinical-trial-for-covid-19-treatments [Accessed 09.07, 2020].

Wu, R., Wang, L., Kuo, H.-C. D., Shannar, A., Peter, R., Chou, P. J., et al. (2020). An update on current therapeutic drugs treating COVID-19. Current Pharmacology Reports 6, 56-70. doi:10.1007/s40495-020-00216-7

Yamasmith, E., Saleh-Arong, F. a.-H., Avirutnan, P., Angkasekwinai, N., Mairiang, D., Wongsawat, E., et al. (2018). "Efficacy and safety of ivermectin against dengue infection: a phase III, randomized, double-blind, placebo-controlled trial," in The 34th annual meeting the royal college of physicians of Thailand 'internal medicine and one health. Pattaya, Thailand: PEACH Royal Cliff Beach Resort.
Young, B. E., Ong, S. W. X., Kalimuddin, S., Low, J. G., Tan, S. Y., Loh, J., et al. (2020). Epidemiologic features and clinical course of patients infected with SARS-CoV-2 in Singapore. JAMA 323, 1488-1494. doi:10.1001/jama.2020. 3204

Zhang, Y., Xiao, M., Zhang, S., Xia, P., Cao, W., Jiang, W., et al. (2020). Coagulopathy and antiphospholipid antibodies in patients with covid-19. N Engl J Med. 382, e38. doi:10.1056/NEJMc2007575

Conflict of Interest: The authors declare that the research was conducted in the absence of any commercial or financial relationships that could be construed as a potential conflict of interest.

Copyright (c) 2021 Kern, Schöning, Chaccour and Hammann. This is an open-access article distributed under the terms of the Creative Commons Attribution License (CC $B Y)$. The use, distribution or reproduction in other forums is permitted, provided the original author(s) and the copyright owner(s) are credited and that the original publication in this journal is cited, in accordance with accepted academic practice. No use, distribution or reproduction is permitted which does not comply with these terms. 